\title{
Radiation Injury After a Nuclear Detonation: Medical Consequences and the Need for Scarce Resources Allocation
}

Andrea L. DiCarlo, PhD; Carmen Maher, MA, CDR-USPHS; John L. Hick, MD; Dan Hanfling, MD; Nicholas Dainiak, MD; Nelson Chao, MD; Judith L. Bader, MD, CDR-USPHS;

C. Norman Coleman, MD; David M. Weinstock, MD

\section{ABSTRACT}

A 10-kiloton (kT) nuclear detonation within a US city could expose hundreds of thousands of people to radiation. The Scarce Resources for a Nuclear Detonation Project was undertaken to guide community planning and response in the aftermath of a nuclear detonation, when demand will greatly exceed available resources. This article reviews the pertinent literature on radiation injuries from human exposures and animal models to provide a foundation for the triage and management approaches outlined in this special issue. Whole-body doses $>2$ Gy can produce clinically significant acute radiation syndrome (ARS), which classically involves the hematologic, gastrointestinal, cutaneous, and cardiovascular/central nervous systems. The severity and presentation of ARS are affected by several factors, including radiation dose and dose rate, interindividual variability in radiation response, type of radiation (eg, gamma alone, gamma plus neutrons), partial-body shielding, and possibly age, sex, and certain preexisting medical conditions. The combination of radiation with trauma, burns, or both (ie, combined injury) confers a worse prognosis than the same dose of radiation alone. Supportive care measures, including fluid support, antibiotics, and possibly myeloid cytokines (eg, granulocyte colony-stimulating factor), can improve the prognosis for some irradiated casualties. Finally, expert guidance and surge capacity for casualties with ARS are available from the Radiation Emergency Medical Management Web site and the Radiation Injury Treatment Network.

(Disaster Med Public Health Preparedness. 2011;5:S32-S44)

Key Words: nuclear detonation, radiation injury, acute radiation syndrome

$\mathrm{T}$ he Scarce Resources for a Nuclear Detonation Project, presented in this issue of Disaster Medicine and Public Health Preparedness, was undertaken to guide community planning for the first 4 days after a nuclear detonation incident. During this period, the demand for resources will vastly outstrip available supplies. The article by Knebel et $\mathrm{al}^{1}$ in this issue includes basic descriptions of nuclear detonation scenarios and a response framework. A nuclear detonation differs from other mass casualty incidents in 2 ways: the very high number of affected individuals and the release of ionizing radiation. Thus, plans for responding to a nuclear detonation must consider the many consequences of radiation (environmental, clinical, and psychological) across a wide population.

The present article briefly reviews pertinent aspects of clinical radiation injury gleaned from reports of human exposure and research in animal models. Specifically, we describe the features of acute radiation syndrome (ARS), outline data supporting a synergistic effect on mortality from radiation in combination with either traumatic injury or cutaneous thermal and/or radiation burns, and discuss evidence for clinical benefit from some facets of sup- portive care, including antibiotics and myeloid cytokines (eg, granulocyte colony-stimulating factor [G-CSF]). To provide context specific to nuclear detonation response, the article includes model-based projections of the number of irradiated casualties, their resource needs, and the anticipated resources available. Subsequent articles in this issue ${ }^{2-4}$ address key aspects of radiation injury management within the context of medical response to a mass casualty event. Because the Scarce Resources for a Nuclear Detonation Project focuses on the initial response after the detonation, the long-term effects of radiation (eg, cancer, teratogenesis, and heritable genetic effects) are not discussed.

\section{IRRADIATED CASUALTIES AND RESOURCES AFTER A NUCLEAR DETONATION}

Computer modeling in Knebel et $\mathrm{al}^{1}$ includes casualty estimates across a range of potential nuclear detonation scenarios. As illustrated in Figure 1, computer modeling of a 10-kT nuclear detonation (identified in the National Planning Scenarios ${ }^{5}$ ) suggests that the zone of significant infrastructure damage would extend approximately $2 \mathrm{mi}$ from ground zero, with glass breakage and traffic crashes beyond $2 \mathrm{mi}$. As such, wider re- 
gional infrastructure would be left largely intact and would contribute to the response. ${ }^{3}$

Despite extended regional capacity, the mismatch between casualties and available resources close to the detonation would be striking. Using Washington, DC, as an example, Tables 1 and 2 include general estimates of demand for and availability of selected resources, using modeling similar to the casualty modeling in Knebel and colleagues. ${ }^{1}$
The limited availability of local resources contrasts starkly with the expected overwhelming demand. For example, approximately 500 vacant functioning adult hospital beds per million people population are available at any given time in the United States. ${ }^{7}$ Based on computer modeling, approximately 1000 beds are vacant within the Washington, DC, metropolitan area, compared with a predicted need for 180000 beds (Table 1). For pediatric patients, the number of vacant beds is closer to 250/ million ${ }^{7}$ and estimates for critical care beds are even lower. For

\section{FIGURE 1}

\section{Approximate prompt radiation and fallout pattern from a 10-kT nuclear detonation}

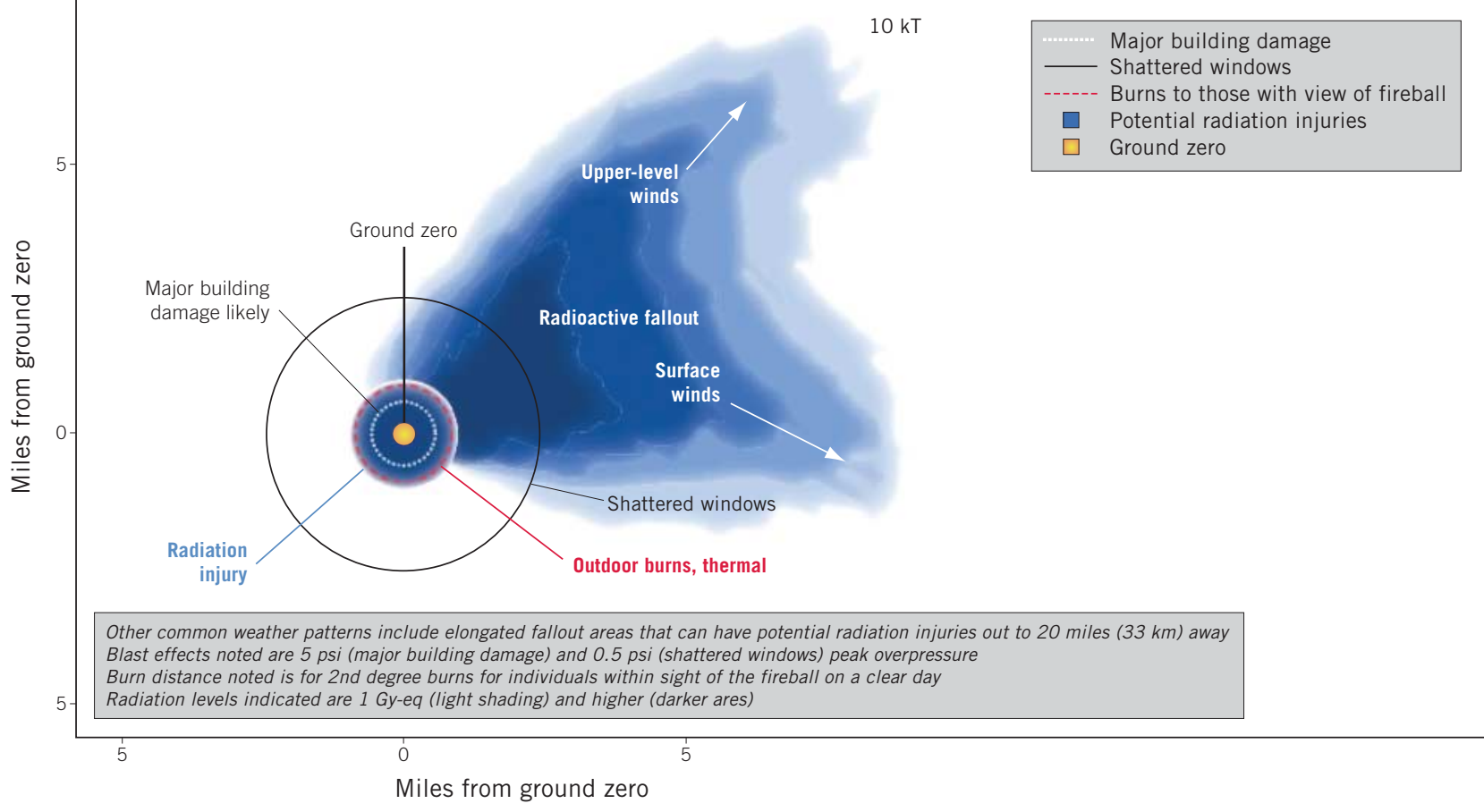

Prompt radiation extends approximately 1 mile from the epicenter, while the shape of the fallout zone is determined by upper-level winds. (Buddemeier 2009.)

\section{TABLE 1}

\section{Resource Demand and Availability after a Nuclear Detonation in Washington, DC}

Symptomatic Injured People or Incident Demand

People injured (next column) or population of designated area (city, nation)

Hospital beds (unoccupied)

Intensive care unit beds (unoccupied)

Operating rooms

Burn beds (unoccupied)

Ambulances Minimum/Median/Maximum

$\begin{array}{cc}\text { Single Hospital } & \text { City } \\ \text { N/A } & 592000 \\ 165(40) & 3670(920) \\ 20.5(1.6) & \text { N/A } \\ 6 & \text { N/A } \\ \text { N/A } & 32(5) \\ \text { N/A } & 38\end{array}$

Nation
$930000 / 990000 / 1.6$ million

$70000 / 180000 / 300000$
$24000 / 61000 / 110000$
N/A
0/0/1100

N/A
38
300 million

$947000(295000)$

118000 (9400)

30000

$1760(580)$

48400

Availability is indicated for a single medical center, within the city, and across the United States. The single-hospital figures are based on an average for medical centers within Washington, DC. Minimum, median, and maximum numbers of people injured and incident demands (second column) are for a variety of 10-kT detonation scenarios in Washington, DC, modeled by the Modeling Division of the Biomedical Advanced Research and Development Authority, Office of the Assistant Secretary for Preparedness and Response, in association with the Public Health Emergency Medical Countermeasures Enterprise Blood and Tissue Requirements Working Group. 
TABLE 2

Needs and Availability for Blood Products and Skin Grafts After a Nuclear Detonation in Washington, DC

\begin{tabular}{|c|c|c|c|c|c|c|c|}
\hline & \multirow{2}{*}{$\begin{array}{l}\text { Average } \\
\text { Daily } \\
\text { Use, US }\end{array}$} & \multirow{2}{*}{$\begin{array}{l}\text { Supply Above } \\
\text { Daily } \\
\text { Use, US }\end{array}$} & \multicolumn{2}{|c|}{$\begin{array}{l}\text { Supply Model for } \\
\text { Washington, DC }\end{array}$} & \multicolumn{3}{|c|}{$\begin{array}{l}\text { Gaps for Washington, DC, } \\
\text { 10-kT Nuclear Detonation } \\
\text { Minimum/Median/Maximum }\end{array}$} \\
\hline & & & Day 1 & Day 2 & Day 1 & Day 2 & Overall \\
\hline Red blood cells, units & 40000 & 160000 & 1000 & 64000 & 47 000/79 000/105 000 & $0 / 17000 / / 42000$ & 47 000/96 000/147 000 \\
\hline Platelets, units & 28500 & 28500 & 160 & 12000 & $38000 / 78000 / 106000$ & $26000 / 69000 / 96000$ & 64 000/3.3 million/5.7 million \\
\hline Skin grafts, cm² $^{2}$ & 20000 & 7.5 million & 340 & 13000 & $0 / 0 / 0$ & 0/0/4.5 million & 0/0/260 million \\
\hline
\end{tabular}

Figures for average daily US use and US supply above daily use are provided for context. The figures for supply and for minimum, median, and maximum gaps in this table are based on research and modeling of a variety of scenarios by the Modeling Division of the Biomedical Advanced Research and Development Authority, Office of the Assistant Secretary for Preparedness and Response in association with the Public Health Emergency Medical Countermeasures Enterprise Blood and Tissue Requirements Working Group.

\section{FIGURE 2}

\section{Hypothetical representation of resource availability (left y-axis) after a nuclear detonation based on location and type of site}

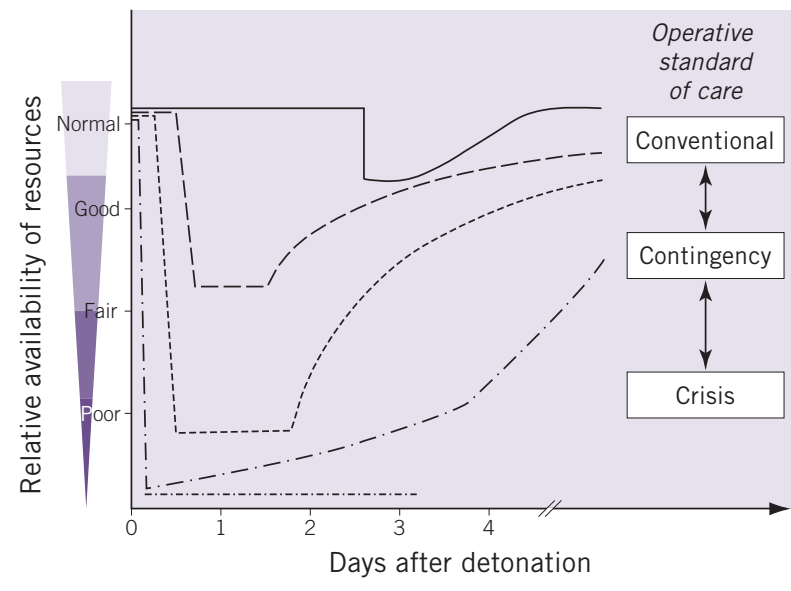

\begin{tabular}{|c|c|}
\hline $\begin{array}{l}\text { Distant referral } \\
\text { center } \\
--- \text { MC } 100 \text { miles away }\end{array}$ & $\begin{array}{l}\text {--- MC } 20 \text { miles away } \\
\text {-- MC } 2 \text { miles away } \\
\text {-..-- RTR } 1\end{array}$ \\
\hline
\end{tabular}

The operative standard of care (right $y$-axis) follows the definitions outlined by the Institute of Medicine. ${ }^{3}$ Centers close to the site would be immediately impacted and require crisis standards of care. RTR1 (Radiation TReatment, TRiage, and TRansport) sites will be established close to the epicenter shortly after the event and may be disbanded after a few days, as salvageable victims are evacuated. Distance from the detonation will be the primary determinant of timing and severity of resource shortages at regional medical centers (MC). Even referral centers in other regions may experience abrupt resource shortages due to patient transfers or depletion of nationwide supplies.

example, only 62 pediatric intensive care unit beds are available on an average day in all of New York City. ${ }^{8}$

Fewer than 100 ambulances serve Washington, DC, proper (Table 1). Thus, the overwhelming majority of people who present for medical care will arrive without assistance from first responders or rescue vehicles. In addition, emergency responder operations will be limited within highly radioactive zones due to radiation and, in some areas, infrastructure damage. ${ }^{5}$ Most severely injured patients with or without radiation injury would not receive life-sustaining medical care quickly, so many would succumb to their injuries. Thus, the effective demand for many resources such as blood products would be far less than estimates of need based solely on the expected numbers and extents of injuries (Table 2).

Resource scarcity after a nuclear detonation will be both location and time dependent. Figure 2 is an illustration of this concept. Because resource availability ( $y$-axis) declines after detonation, the operative standard of care (defined by the Institute of Medicine ${ }^{9}$ ) transitions from conventional to contingency to crisis. The 5 curves represent different medical care settings that vary by distance from the epicenter. A radiation treatment, triage, and transport (commonly known as RTR1) site (outlined in Knebel et $\mathrm{al}^{1}$ ) that forms close to the detonation is likely to have drastic resource scarcities and then disband after evacuation is complete. Resource scarcity at local medical care sites will improve with time after the detonation, but they may not reach normal levels for an extended period. Regional hospitals will differ in their availability of resources based on location relative to the detonation and their role in the community (eg, trauma or pediatric center). Finally, hospitals and referral centers distant from the incident may not be affected for several days, but they may face shortages or be overwhelmed as casualties arrive at their centers or supplies cannot be replenished due to intense demand.

\section{ARS}

The effects of radiation are dependent on the overall dose, dose rate, radiation quality, and fraction of the body that is irradiated. Higher doses (Gray units are used, which equal $100 \mathrm{rad}$ ), greater dose rates $(\mathrm{Gy} / \mathrm{h})$, and irradiation to larger fractions of the body produce greater injury. The same radiation exposures can cause drastically different signs and symptoms across a population. ${ }^{11}$ Many genetic, demographic, dietary, and other factors can contribute to the manifestations of radiation injury, but most of the interindividual differences are poorly understood. Thus, although radiation exposure is used to guide triage and initial management, the overall management for each person will depend on his or her medical course and the availability of resources. ${ }^{3}$ 
As outlined by Knebel and colleagues ${ }^{1}$ and illustrated in Figure 1, 2 groups of casualties would be exposed to radiation after a nuclear detonation. The first group is within 1 to $2 \mathrm{~km}$ of a $10-\mathrm{kT}$ blast and would receive a high dose of prompt irradiation released in a circumferential pattern at an extremely high dose rate. Because of their proximity to the explosion, many of the casualties exposed to prompt irradiation would also sustain traumatic and/or burn injuries. ${ }^{1,12}$

The second group of irradiated casualties would be exposed in the fallout zone downwind of the detonation, where radioactive fallout from the mushroom cloud would contaminate the environment. ${ }^{5}$ The dose rate of fallout radiation is lower than that for prompt radiation and decreases rapidly with time. ${ }^{12}$ The clinical consequences of fallout radiation at a given dose may be significantly fewer than for the same dose of prompt irradiation because of the lower dose rate from radioactive fallout. In addition, many of the individuals exposed within the fall- out zone would have radiation injury only and lack trauma or burns.

Mild symptoms may develop after whole-body radiation exposures as low as $1 \mathrm{~Gy}$. Casualties exposed to $>2$ Gy are at risk for developing clinically significant ARS. ARS represents a constellation of signs and symptoms that occur between several minutes and several weeks after exposure. ${ }^{10,11,13}$ ARS primarily involves the 4 organ systems with the greatest acute sensitivity to ionizing radiation: hematologic, gastrointestinal, cutaneous, and cardiovascular/central nervous systems. Figure 3 illustrates the nature and time course of symptoms, which can vary based on radiation dose. The signs and symptoms of radiation exposure mimic those observed after therapeutic whole-body irradiation or treatment with clastogenic chemotherapy and can range from mild nausea at low doses to rapid neurovascular collapse at high doses (ie, >10-20 Gy). While specific organ syn-

\section{FIGURE 3}

\section{Simplified time courses for hematologic, gastrointestinal (GI) and central nervous system (CNS) symptoms at different whole-body dose exposures}
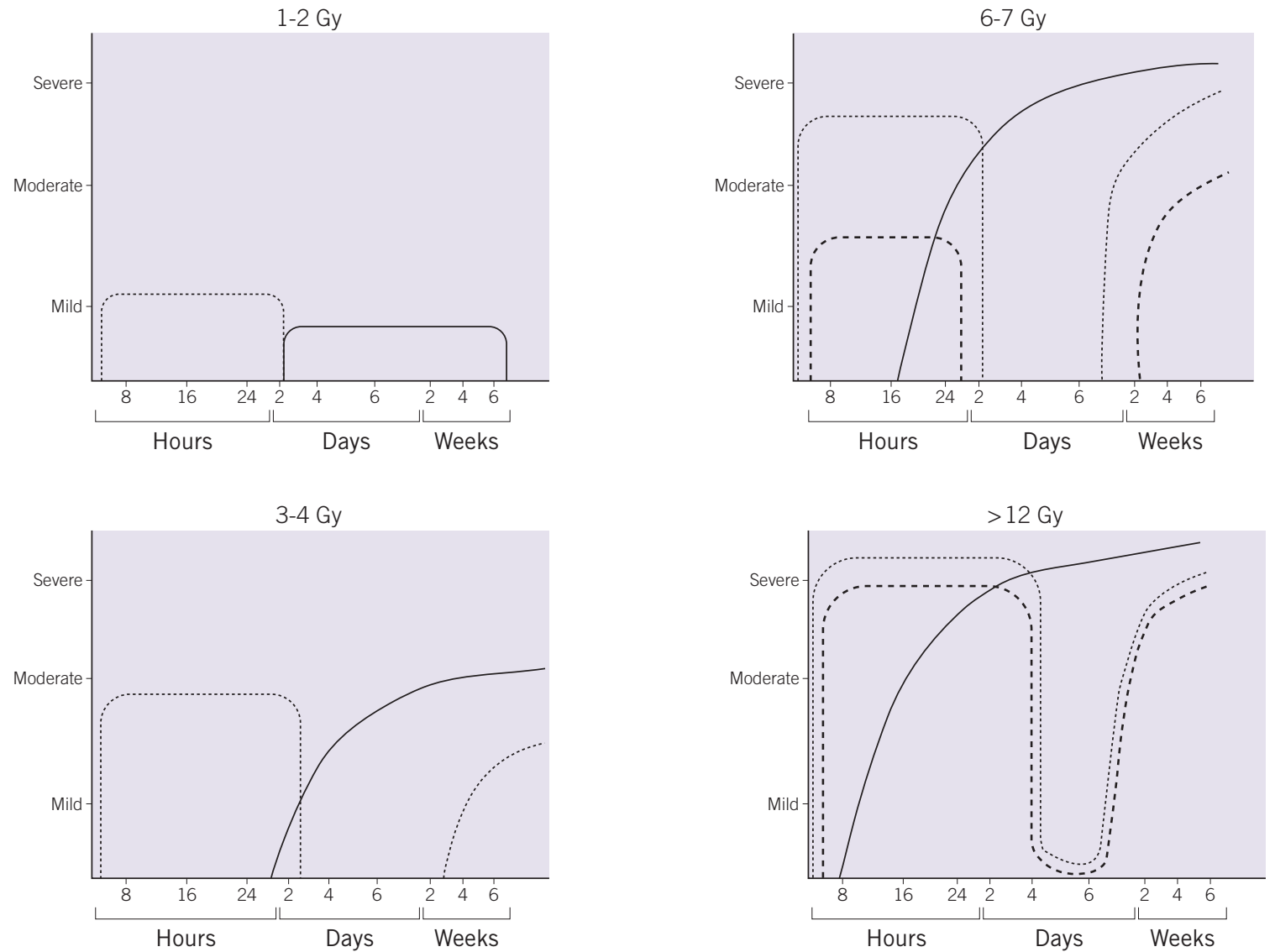

_- Hematologic changes …-.... Gl symptoms --.-- CNS symptoms

The relative severity of signs and symptoms is on an arbitrary scale. (Modified from Waselenko ${ }^{10}$ ). 
dromes are discussed, multiorgan effects may mediate many clinical signs and symptoms. ${ }^{14}$

ARS classically progresses through 4 clinical phases: prodrome, latency, manifest illness, and either recovery or death. The prodromal period is characterized by nausea, vomiting, fatigue, and, at higher doses, autonomic instability and even loss of consciousness..$^{15}$ The latency period is characterized by partial or complete resolution of symptoms. The extent and duration of latency are inversely proportional to dose. Casualties who receive doses $>6$ Gy may have little or no latency because signs and symptoms of end-organ injury can develop within hours to days after exposure.

Peripheral blood cytopenias can develop at doses as low as $1 \mathrm{~Gy}$ (Figure 3) due to the heightened apoptotic response of both differentiated and progenitor hematopoietic cells. ${ }^{16}$ The rapidity of onset and severity of peripheral blood cytopenias are proportional to dose. Lymphocytes are particularly sensitive to irradiation and the kinetics of lymphocyte depletion is a useful parameter for rapidly assessing the extent of radiation exposure. ${ }^{3}$ Importantly, patients experiencing burns or trauma may develop lymphopenia in the absence of radiation exposure. ${ }^{17,18}$

White blood cell counts may also follow a predictable time course depending on the extent of exposure (Figure 4). Evidence from radiation accident casualties indicates that a transient increase in granulocyte count (an "abortive rise") preceding a slow decline for 10 to 15 days may indicate reversible hematologic ARS, and thus a higher likelihood of survival (Figure 4). In contrast, irreversible hematologic ARS (ie, myeloablation) follows a different pattern of granulocyte kinetics, with a rapid fall between 4 and 6 days after exposure. ${ }^{19}$ In a review of 60 radiation accident casualties with granulocyte kinetics that were consistent with reversible hematologic ARS, all 60 ultimately achieved autologous hematopoietic recovery, although in some cases not until 60 to 80 days after exposure. ${ }^{19}$

Many radiation accident casualties received heterogeneous doses from partial-body shielding. Similar heterogeneity may be common in casualties exposed to prompt irradiation from a nuclear detonation because the radiation may be blocked by buildings and other structures. If small areas of bone marrow are relatively spared by partial shielding, then hematologic reconstitution may occur even if the vast majority of the marrow receives a dose that is adequate to confer irreversible injury. Dose heterogeneity may be less prevalent among casualties exposed to fallout because fallout would broadly contaminate the environment.

Although whole-body doses as low as 2 Gy can cause clinically significant ARS, both the timing of death and the organ system most likely to mediate death differ between lower and higher dose exposures. Death from hematologic ARS can occur with exposures between 2 and $6 \mathrm{~Gy}$ as a result of infection and/or bleeding from neutropenia and thrombocytopenia, respectively. The long circulating life span of red blood cells makes anemia less of an is- sue in the early period after radiation exposure. Death from hematologic ARS typically occurs between 2 and 8 weeks after exposure. ${ }^{10}$ At doses $>5$ to 6 Gy, gastrointestinal ARS may cause death through extensive diarrhea and transmigration of enteric organisms into the bloodstream, typically within 1 to 2 weeks of exposure..$^{20}$ Symptoms of gastrointestinal ARS include nausea, vomiting, and diarrhea; however, nausea and vomiting are nonspecific symptoms that can occur at lower doses or even in the absence of radiation..$^{21}$ At doses $>8$ to $10 \mathrm{~Gy}$, death resulting from cardiovascular/central nervous system ARS may occur within days after exposure; symptoms include headache, confusion, loss of consciousness, seizures, and autonomic instability. ${ }^{10}$

The $\mathrm{LD}_{50 / 60}$ (dose at which only $50 \%$ of humans will survive at least 60 days) for adults in the absence of supportive care is approximately $3.5 \mathrm{~Gy} .{ }^{10,22}$ Death at this dose would primarily result from hematologic ARS and would occur 2 to 6 weeks after exposure. ${ }^{10,22}$ Casualties who survive long enough for hematologic reconstitution are likely to fully recover. In contrast, much higher doses lead to earlier death and almost no likelihood of full recovery. A Nuclear Regulatory Commission study ${ }^{23,24}$ estimated that the $\mathrm{LD}_{50 / 7-14}$ for humans is $9.6 \mathrm{~Gy}$ (95\% confidence interval, 5.7-17.2 Gy). Death from this higher dose occurs within 7 to 14 days because of serious gastrointestinal tract and possibly cerebrovascular injury, in addition to potentially irreversible hematologic ARS. As outlined below, interventions for hematologic ARS, including fluid support, antimicrobials, and transfusions, may increase the $\mathrm{LD}_{50 / 60}$ to 600 to 700 $\mathrm{cGy},{ }^{7}$ but it remains unclear whether any available intervention can reduce early death after higher doses.

ARS in organ systems other than the hematologic, cutaneous, gastrointestinal, and neurovascular may be underappreciated, especially in casualties exposed to higher doses. In a review of radiation accident casualties, 32 of 45 cases with severe ARS had respiratory involvement, 20 had cardiovascular involvement (primarily manifested as heart failure), 25 had liver involvement, and 32 had urogenital involvement. ${ }^{8}$ Delayed effects of acute radiation exposure, which can involve almost any organ system, can develop months to years after exposure.

\section{SOURCES OF DATA ON RADIATION INJURY}

Despite more than 6 decades of research, major gaps exist in our understanding of how genetic, demographic, geographic, and other factors would affect radiation injuries after a nuclear detonation in a modern US city. The available literature on radiation injury derives from 4 sources of observational and experimental research, and was largely collected in the 1950s and 1960s. None of the 4 sources fully captures the spectrum of injuries expected after a ground-level nuclear detonation within a modern US city, but each provides some insights.

\section{Nuclear Bomb Detonations}

Cohorts of nuclear bomb casualties from the Hiroshima and $\mathrm{Na}$ gasaki detonations have been followed for more than 6 decades. Up to $70 \%$ of casualties postdetonation had combined injury (ie, 
radiation plus trauma and/or burns) ${ }^{25-27}$; however, the detonations at Hiroshima and Nagasaki were both air bursts. Air bursts produce higher rates of combined radiation and burn injury than would be expected after a ground-level detonation, which is the type of event specified in National Planning Scenario 1. ${ }^{5}$ In addition, both Japanese cities contained primarily wooden structures, so building collapse and secondary fires were more common than would be anticipated in a modern US city. ${ }^{5}$ As a result, lower rates of combined injury are expected in current scenarios, especially within the fallout zone. ${ }^{1}$ Most important, little medical care was available in the aftermath of the Hiroshima and $\mathrm{Na}$ gasaki detonations, making it difficult to estimate the potential benefits of supportive care interventions.

\section{Medical and Industrial Radiation Accidents}

Between 1944 and 2003, there were 426 major radiation accidents worldwide involving more than 130000 people. ${ }^{28}$ Nearly $90 \%$ of the exposures resulted from the Chernobyl accident in 1986. Most of the other accidents led to only a few casualties. As a result, extensive resources and supportive care were available to treat those injured by these smaller-scale accidents. Databases on radiation accident casualties, including 1 at the Radiation Emergency Assistance Center/Training Site $)^{29}$ have been established but are not open access. The SEARCH database, established by the University of Ulm, contains details from more than 800 wholebody radiation exposures from 70 accidents. ${ }^{19}$ Data from SEARCH was used by the European Medical Treatment Protocols effort to establish triage and treatment approaches for radiation accident casualties, ${ }^{11}$ as outlined for granulocyte kinetics above.

There are important shortcomings in the literature of radiation accidents that limit its applicability to nuclear detonation response planning. First, there were no standardized approaches applied to the casualties. Treatment was essentially ad hoc, and each center used different combinations of cytokines, antibiotics, and even cellular therapies. Thus, the interpretation of outcomes and even the relations between dose and clinical parameters, are highly confounded. Second, the nature of radiation injury is likely to differ between radiation accident and nuclear detonation casualties. For example, the fraction of radiation from neutrons was significantly higher in industrial accidents like the Tokaimura accident than would be expected after a nuclear detonation. ${ }^{30}$ Finally, industrial radiation accidents affect primarily relatively young healthy men, so the effects of a particular exposure across a range of demographic groups cannot be determined.

\section{Therapeutic Radiation}

The third source of information on radiation injury (and the benefit of targeted radiation countermeasures) is from patients who have been treated with therapeutic radiation. Extrapolation from the therapeutic radiation experience to nuclear detonation scenarios is also problematic. Patients treated with therapeutic radiation commonly have underlying illnesses (primarily cancer) that affect their overall health, response to radiation, and recovery. These patients are frequently receiving other agents, such as

\section{TABLE 3}

$\begin{array}{lcc}\text { Comparison of } \mathbf{L D}_{50 / 30} \text { Across Multiple Mammalian } \\ \text { Species Compiled From the Published Literature } \\ \text { Species } & \text { LD }_{50 / 30} \text {, cGy } & \text { Mean survival times, d } \\ & 240 & \text { ND } \\ \text { Goat } & 250 & 17 \\ \text { Swine } & 250 & 15 \\ \text { Dog } & 255 & \text { ND } \\ \text { Burro } & 450 & 12 \\ \text { Guinea pig } & 600 & 14 \\ \text { Monkey } & 610 & \text { ND } \\ \text { Hamster } & 640 & 10 \\ \text { Mouse } & 705 & \text { ND } \\ \text { Mouse (germ-free) } & 714 & 12 \\ \text { Rat } & 750 & 10 \\ \text { Rabbit } & 856 & \text { ND } \\ \text { Hamster } & 1000 & 10 \\ \text { Mongolian gerbil } & \end{array}$

All survival times are approximate. $\mathrm{ND}=$ no data available.

chemotherapy, that further complicate interpretation of the effects from radiation. In addition, most therapeutic radiation is highly focused on a limited portion of the body and given in multiple fractions to minimize toxicity. Even in the setting of total body irradiation for hematopoietic stem cell transplantation (HSCT), partial shielding of radiosensitive organs, such as the lungs, is common. Finally, therapeutic radiation is provided at expert centers as part of a comprehensive approach designed to maximize efficacy while minimizing toxicity. Thus, many patients treated with therapeutic radiation will also receive supportive care, myeloid cytokines (eg, G-CSF), and even HSCT.

\section{Animal Models}

The use of human data to plan for nuclear detonation response avoids the need to extrapolate from results in animal models; however, animal models are essential for prospective research, including the evaluation of potential radiation countermeasures. ${ }^{31-33}$ As outlined in Table 3, the sensitivity of different mammalian models to wholebody irradiation varies considerably, with $\mathrm{LD}_{50 / 30}$ ranging between 240 and $1000 \mathrm{cGy}$. The variability in effect that radiation exposure has on individuals, the potential for combined injuries to affect radiation outcomes, and interspecies variability make it extremely difficult for a single animal model to capture the effects of radiation exposure and predict medical countermeasure efficacy with adequate fidelity. Thus, a variety of animal species have been used. It is important to note that depending on the radiation syndrome being analyzed, different models and/or strains may be appropriate. For example, swine are widely considered to be the most appropriate human surrogates for studies involving radiation injury to skin. ${ }^{34-36}$

Rodent models, particularly mice, have been used extensively for mechanistic and proof-of-concept studies and to evaluate new and existing radiation medical countermeasures (MCMs). Rodent models are relatively inexpensive, readily available in a wide selection of genetic backgrounds, and can be studied humanely using survival as an endpoint. A primary shortcoming of all of the ro- 
dent models is the challenge of providing supportive care similar to what may be provided to a human patient.

As noted in Table 3, the average $\mathrm{LD}_{50 / 30}$ for mice exposed to wholebody gamma irradiation is $640 \mathrm{cGy}$, but it ranges between 540 and $850 \mathrm{cGy}$ depending on the strain (Figure 4). Other strainspecific differences have been noted in radiation response. For example, a recent report investigating the development of radiationinduced, late lung complications in different strains of mice found that certain strains were more representative of human responses than others ${ }^{38}$; for example, C57BL/6 mice exhibited pleural effusions at 6 to 9 months, which are not normally observed in irradiated humans. Rat models are useful for determining the pharmacokinetics and pharmacodynamics of candidate MCMs, but there is less literature available to support their use as an ef- ficacy model for radiation syndromes. Nonetheless, rats have a long track record as the preferred animal models for studies of radionuclide decorporation. ${ }^{39}$

Canines (especially beagles) have been studied extensively as animal models of hematologic $\mathrm{ARS}^{40}$ and for radionuclide decorporation. ${ }^{41}$ Canines have radiation responses similar to humans and respond well to supportive care and antibiotics. ${ }^{15,42}$ Other animal models for testing radiation effects and potential MCMs have been described in the published literature, including ovine, avian, bovine, equine, and a wide array of nonhuman primate species, especially the rhesus macaque. The latter now represents the gold standard for most acute radiation and MCM studies because of its close evolutionary relation to humans and the similar effects of supportive care (Table 4). ${ }^{31}$

FIGURE 4

Leukocyte counts based on exposure dose in patients exposed to radiation in Chernobyl

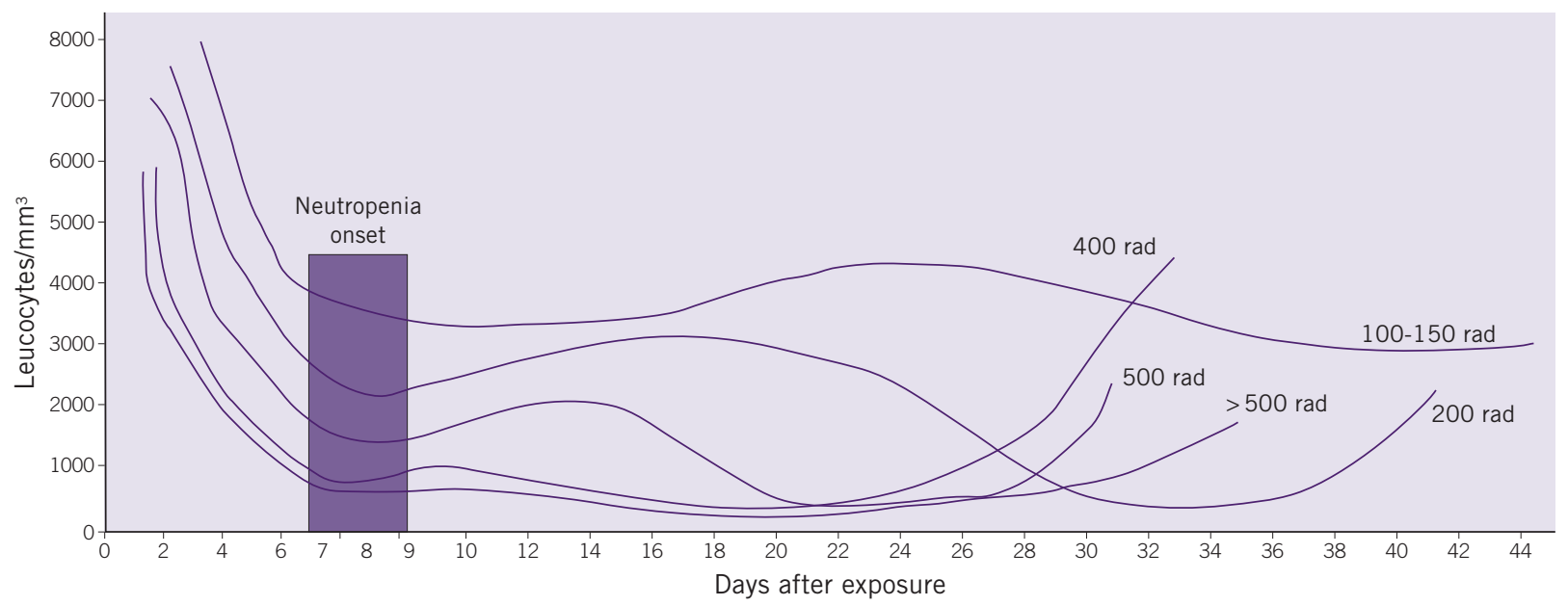

Note that doses less than $5 \mathrm{~Gy}$ are associated with an early abortive rise (transient increase) in leukocytes, which are primarily composed of granulocytes. The onset of neutropenia may not occur for weeks, especially with lower exposures, and the duration of neutropenia may be prolonged. (Modified from Vorobiev 1997.)

\section{$\mathrm{LD}_{50}$ Values (Gy) for Humans and Rhesus Monkeys Exposed to Different Radiation Types, With Different Levels of Supportive Care}

\begin{tabular}{|c|c|c|c|c|c|c|c|c|c|}
\hline \multirow[b]{3}{*}{ Species } & \multicolumn{3}{|c|}{ Pure $\gamma \mathrm{LD}_{50}$} & \multicolumn{3}{|c|}{ x-ray LD D $_{50}$} & \multicolumn{3}{|c|}{ Mixed $\gamma$ and Neutron $\mathbf{L D}_{50}$} \\
\hline & \multicolumn{3}{|c|}{ Level of Support } & \multicolumn{3}{|c|}{ Level of Support } & \multicolumn{3}{|c|}{ Level of Support } \\
\hline & None & Normal & Heroic & None & Normal & Heroic & None & Normal & Heroic \\
\hline Human & ND & $4.7^{43}$ & ND & ND & ND & ND & $3.1^{44}$ & $4.1,{ }^{22} 4.1^{45}$ & $8.9^{46}$ \\
\hline Rhesus & $4.4,{ }^{47} 6.4^{*}$ & ND & ND & $4.8^{48-51 *} 6.7^{52}$ & $4.9,,^{33} 5.3^{54}$ & $9^{54}$ & $4,,^{55} 3.8^{56}$ & $2.6^{54}$ & $4.4^{54}$ \\
\hline
\end{tabular}

Support levels indicated are based on a report by the Nuclear Regulatory Commission, which defined 3 levels of care: minimal, supportive, and heroic. For the purposes of the studies discussed here, no support represents little (human), or no (rhesus) intervention, and normal support is the administration of fluids, blood products, antibiotics, and, in some cases, parenteral nutrition. Heroic support is defined as comprehensive, individualized care, including hematopoietic stem cell transplant. Even with these definitions in place, subtle differences in the level of supportive care given to irradiated animals and humans can have substantial effects on morbidity and mortality. $L D_{50}$ values are given as $L D_{50 / 60}$ for humans and $L D_{50 / 30}$ for rhesus monkeys. ND indicates no data available. Free-in-air dose $22,43-45 ;$ high dose rate (8 Gy/min) total-body $\gamma$-radiation exposure ${ }^{47}$; moderate dose rate (50 cGy/min) total-body exposure*; average $\mathrm{LD}_{50 / 30}$ for referenced studies (free-in-air dose at skin surface) ${ }^{48-51} ; 2 \mathrm{MeV}$, high-energy x-irradiation (approximates ${ }^{60} \mathrm{Co} \gamma$-irradiation) ${ }^{52,53}$; bone marrow transplant ${ }^{54}$; nuclear detonation, high dose rate, and mixed neutron: $\gamma$ ratio unreported ${ }^{55}$; mixed neutron: $\gamma$-radiation from TRIGA reactor (General Atomics Electronic Systems, San Diego, CA). ${ }^{56}$

*Data from T. J. MacVittie, personal communication. 


\section{ADDITIONAL FACTORS AFFECTING OUTCOME}

Studies in animal models have established several radiationand organism-specific determinants of radiation response. Presumably, these same determinants affect humans exposed to radiation. The factors include the range of doses selected, radiation quality, dose rate, and the fraction of the body exposed (eg, partial vs total body). Even the time of day of irradiation can affect outcome. ${ }^{57}$ In animal models, sex and age can alter not only the outcome after radiation exposure but also pharmacologic parameters important for an MCM, such as clearance, metabolism, and safety profile. Female rodents, in general, have decreased radiation $\mathrm{LD}_{50 / 30}$ values as compared with their male counterparts. ${ }^{58,59}$ The age of rodents ${ }^{60,61}$ and canines $^{62}$ at the time of irradiation significantly influences their radiation sensitivity, with $\mathrm{LD}_{50 / 30}$ values for mice ranging nearly 4-fold, from 210 to $740 \mathrm{cGy}$, depending on age at the time of irradiation. As expected, the health status of the animals within a colony can affect radiation response. $\mathrm{LD}_{50 / 30}$ values are substantially lower for mice exposed to conventional environmental pathogens than for animals maintained in "pathogen-free" environments. ${ }^{63}$ Even the type of food and water administered to animals can affect their radiation response. ${ }^{64}$

\section{Radiation Combined Injury}

Based on multiple animal models and observations in humans, the combination of radiation with either trauma or burns markedly increases mortality compared with the same dose of radiation alone. Outcomes among casualties of the Chernobyl accident with combined injury were universally poor. ${ }^{65}$ In a study by Ledney, ${ }^{66}$ the $\mathrm{LD}_{50 / 30}$ in mice for radiation alone was approximately 963 cGy but dropped to 820 cGy when combined with an otherwise nonlethal $15 \%$ body surface area burn. ${ }^{67} \mathrm{LD}_{50 / 30}$ dropped from 963 cGy to 761 cGy when radiation was combined with an otherwise nonlethal puncture wound. A similar study of radiation with or without nonlethal wound is outlined in Figure 5.

In canines, a $20 \%$ body surface area burn would result in minimal mortality, but mortality increases to $73 \%$ if the same burn is combined with only $1 \mathrm{~Gy}$ of whole-body irradiation. ${ }^{68}$ In rats, lethality from a burn increased from $50 \%$ when the burn was administered alone to $65 \%$ when combined with 1 Gy and $100 \%$ when combined with $2.5 \mathrm{~Gy} .{ }^{69}$ Similar findings were reported when burn was combined with radiation in pigs ${ }^{70}$ or guinea pigs. ${ }^{71}$

The additional mortality from combined injury likely results, at least in part, from infection by enteric organisms. Sublethal wound or burn injury increases the translocation of gut bacteria into the bloodstream induced by sublethal irradiation. ${ }^{72,73}$ Whitnall et al ${ }^{74}$ reported that sublethal doses of both radiation and Klebsiella pneumoniae administered to mice produce $100 \%$ mortality because of sepsis. In fact, even doses of radiation as low as 0.5 Gy increase the mortality from bacterial infection in this model. ${ }^{74}$ Wound closure is also delayed by radiation in a dose-dependent manner, ${ }^{75}$ increasing the potential for infection from a cutaneous source after either burn or traumatic injury.

\section{Supportive Care}

Current data suggest that supportive care can be an extremely effective radiation countermeasure. ${ }^{42}$ Supportive care in animal studies may be generally classified as "normal support," defined as administration of fluids, blood products, antibiotics, and in some cases parenteral nutrition, or "heroic support," defined as comprehensive, individualized care up to and including cytokines and HSCT. In addition, the management of combined injuries, both surgical and nonsurgical, is an essential component of supportive care.

A series of studies has demonstrated the efficacy of antibiotic support and platelet transfusions in dogs exposed to radiation, ${ }^{76-78}$ either in randomized trials or when compared with historical controls followed without supportive care. Antibiotics also improve survival in mice after combined injury. ${ }^{37}$ Even topical antibiotics can improve survival after combined radiation and wound injury. Figure 5 demonstrates the efficacy of topical silvadene or gentamicin applied to wounded mice also ex-

\section{FIGURE 5}
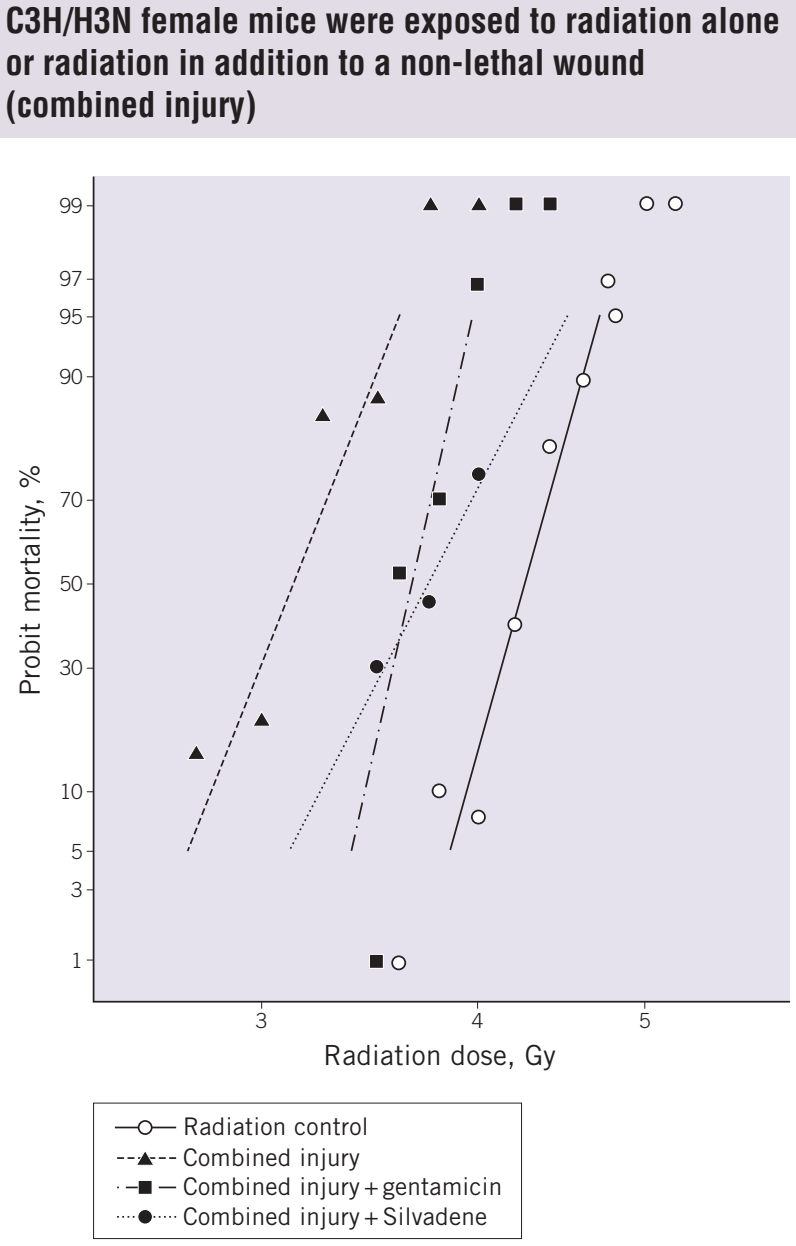

The combination increased mortality at all doses, but mortality was reduced by applying topical gentamicin or silvadene. (Modified from Ledney. ${ }^{62}$ ) 
posed to varying doses of radiation. ${ }^{37}$ This suggests a direct effect on survival from infection by cutaneous organisms, even at low doses, and the potential for simple interventions to improve outcome.

Supportive care in irradiated humans has been estimated to increase $L_{50 / 60}$ values from approximately 3.5 to $4 \mathrm{~Gy}$ up to approximately 6 to $7 \mathrm{~Gy}^{13}$ (Table 4). The $\mathrm{LD}_{50 / 60}$ after the Chernobyl incident was $8.88 \mathrm{~Gy}$, although many casualties received relatively low dose rates ${ }^{22}$ and some underwent HSCT. ${ }^{80}$ Recommended approaches for antibiotic and myeloid cytokine use (for both prophylaxis and treatment) after radiation exposure largely follow algorithms for the treatment of chemotherapy-associated neutropenia. ${ }^{13,14,81}$ Of note, the management of patients with severe ARS, combined injuries, or both is highly labor and resource intensive; a single casualty of the Tokaimura radiation accident required abundant personnel and resources for comprehensive and intensive care, including approximately $10 \mathrm{~L}$ of fluid daily and extensive transfusion support. ${ }^{82}$ Presumably, resource scarcities after a nuclear detonation would greatly reduce the number of casualties who could receive this level of support.

\section{Cytokine Therapy}

Myeloid cytokines enhance neutrophil recovery in patients with neutropenia. Three myeloid cytokines are approved by the Food and Drug Administration for the management of chemotherapyassociated neutropenia: granulocyte-colony stimulating factor (G-CSF), granulocyte macrophage-colony-stimulating factor (GM-CSF), and pegylated G-CSF. Note that these agents are not approved by the Food and Drug Administration for use after a nuclear detonation but would likely be used either under an emergency use authorization or off-label, as discussed by Murrain-Hill and colleagues. ${ }^{4}$

In a meta-analysis of trials that used G-CSF for patients treated with chemotherapy for solid tumors or lymphoma, ${ }^{83} \mathrm{G}$-CSF reduced infection-related mortality by $45 \%$ from an absolute frequency of $2.8 \%$ to $1.5 \%$. Although this absolute benefit is small, in a scarce resources setting, the prevention or shortening of febrile neutropenia would offer the added benefit of reducing the need for additional medical care, including inpatient hospitalization. In the meta-analysis, G-CSF reduced the frequency of febrile neutropenia from $39.5 \%$ to $22.4 \%,{ }^{83}$ suggesting a significant potential for benefit.

Studies in irradiated primates have consistently demonstrated more rapid neutrophil recovery after irradiation in animals treated with myeloid cytokines. ${ }^{10}$ In rhesus macaques, G-CSF or GM-CSF increased overall survival after irradiation when given for 14 to 21 days. ${ }^{84-86}$ Some reports have suggested that the survival benefit is maximized if myeloid cytokines are initiated within 24 hours after exposure. Studies to verify this possibility are planned or in progress.

G-CSF and GM-CSF have been used in a subset of radiation accident casualties. In a series of 28 cases compiled by the Ra- diation Emergency Assistance Center/Training Site, neutrophil recovery appeared to have been hastened in 25; however, many of these casualties received both agents and some also received interleukin- $3 .{ }^{10}$ Myeloid cytokines may be beneficial even several weeks after exposure. Recently, 2 radiation accident casualties were treated with cytokines beginning as late as 28 days after exposure and both had rapid responses with complete correction of neutropenia. ${ }^{81}$

Few states have plans for response to a nuclear detonation, ${ }^{28}$ but even among states that do, stockpile targets for individual hospitals are in the range of 150 doses of myeloid growth factors and antibiotics, ${ }^{29}$ compared with the hundreds of thousands of casualties expected to sustain radiation injury (Table 1 ). Thus, it is essential to use thoughtful, effective triage protocols for selecting which casualties should receive myeloid cytokines from local caches or from rapid deployments from the Strategic National Stockpile. Triage guidelines along with recommendations for myeloid cytokine use are included in the article by Coleman et $\mathrm{al}^{2}$ in this issue.

Ideally, casualties who qualify for myeloid cytokines should initiate a treatment course within approximately 24 hours after exposure. Because early administration of the first dose appears to be important, it is essential to develop approaches for rapidly offering these agents to as many significantly irradiated casualties as possible. A user-managed inventory concept is being developed (C. N. Coleman, personal communication, 2010) that would make additional drugs available locally at a number of medical facilities by virtue of maintaining a bubble in the supply line of dual-use drugs, such as cytokines used in cancer therapy. This would result in more first doses available early after the detonation so that treatment of irradiated casualties could be initiated locally and then be referred to less resource-scarce settings to receive the remaining doses. In so doing, a 10-day course for 1 person locally becomes a 1 -day course for 10 people, who can be evacuated and then receive subsequent doses in a more resource-rich setting.

The initial dose-finding studies of G-CSF demonstrated a clear linear dose-response effect. ${ }^{68-70}$ Thus, approaches to extend the number of recipients by reducing the dose, extending the interval between doses, or abbreviating the course of therapy are likely to compromise efficacy and should be avoided. Children with ARS will also benefit from myeloid cytokines, so stockpiles should include formulations with dosing flexibility.

\section{HSCT}

Some casualties of a nuclear detonation will receive sufficient doses of radiation to cause irreversible bone marrow damage. Allogeneic HSCT in this setting has the potential to restore hematopoietic function. It remains unclear, however, whether HSCT has the potential to improve survival in radiation casualties, especially those with traumatic and/or burn injuries. HSCT has demonstrated a survival benefit in animal models ${ }^{37}$; however, animals in these 
studies typically received syngeneic (or highly genetically similar) stem cell transplants, which eliminates or markedly reduces the likelihood of graft-vs-host disease.

To date, 31 patients have undergone allogeneic HSCT after accidental whole-body radiation exposure. The preparative regimens given, if any, varied widely, as did antibiotics and graft-vshost disease prophylaxis. ${ }^{28,87}$ The median survival after transplantation among these patients was approximately 1 month. Only 4 patients survived 1 year after HSCT; all 4 rejected the transplant and reconstituted autologous hematopoiesis, suggesting that the transplant offered little benefit. Among the 31 HSCT recipients, graft-vs-host disease contributed to mortality in more than $20 \%$. It is unknown whether any of the casualties who succumbed to transplant-related complications would have reconstituted autologous hematopoiesis if the transplant had been withheld. Thus, there is no evidence that HSCT improves survival in humans exposed to nontherapeutic radiation.

\section{GUIDANCE AND SURGE CAPACITY FOR IRRADIATED CASUALTIES}

The detonation of a nuclear device within a US city would create a national need for health care practitioners to manage casualties exposed to radiation; however, only a small fraction of practitioners have either training or experience in the field of radiation injury.

\section{Radiation Emergency Medical Management Web Site}

To establish a resource for pre- and postevent information, training and communication, the Department of Health and $\mathrm{Hu}$ man Services (DHHS) launched the Radiation Emergency Medical Management (REMM) Web site in March 2007. ${ }^{88}$ Recognizing the limitations of available human and animal data as an evidence base for guiding medical management, REMM has the following goals:

- Provide guidance for health care providers, primarily physicians, about clinical diagnosis and treatment of radiation injury during radiological and nuclear emergencies

- Provide just-in-time, evidence-based, usable information with sufficient background and context to make complex issues understandable to those without formal radiation medicine expertise

- Provide Web-based information that is also downloadable in advance so that it would be available during an event if the Internet is not accessible

Since its establishment, REMM content has expanded significantly and REMM versions have been launched for various mobile platforms. ${ }^{89}$ The primary managers of the site are content and technology experts at various DHHS agencies, including the National Cancer Institute, the National Library of Medicine, the Centers for Disease Control and Prevention, and the Office of the Assistant Secretary for Preparedness and Response, which has its own public health emergency Web site (http://www.phe.gov/preparedness/Pages/default.aspx).
Guidelines for the diagnosis and management of radiation injury are included on the REMM site and extensively referenced from the peer-reviewed literature. Template admission orders for irradiated casualties are also available (http://www .remm.nlm.gov/adultorderform.htm) and include antibacterial, antifungal, and antiviral prophylaxis; decorporation agents; myeloid cytokines; and other elements of radiation casualty management. Content from the Scarce Resources for a Nuclear Detonation Project outlined in this special issue of Disaster Medicine and Public Health Preparedness is being incorporated into the site.

\section{Radiation Injury Treatment Network}

Many of the casualties with radiation-only injury will be salvageable but require outpatient and/or inpatient care. Recognizing this, the US National Marrow Donor Program, the US Navy, and the American Society for Blood and Marrow Transplantation collaboratively developed the Radiation Injury Treatment Network (RITN), which comprises 55 HSCT centers, stem cell donor centers, and umbilical cord blood banks across the United States. ${ }^{90,91}$ The goals of RITN are to develop treatment guidelines for managing hematologic toxicity among victims of radiation exposure, to educate health care professionals about pertinent aspects of radiation-exposure management, to assist in coordinating the medical-situation response after a radiation event, and to provide comprehensive evaluation and treatment for victims at participating centers.

In recent tabletop exercises, ${ }^{90} \mathrm{RITN}$ centers volunteered to provide surge capacity for $<2000$ total irradiated people at their institutions. Strategies to increase bed availability and extend staff and resources could increase surge capacity 10 -fold but would require changes in operating standards. ${ }^{90}$ Considering the large number of irradiated casualties anticipated after a nuclear detonation (Figure 1), many centers across the country in addition to those in RITN will be asked to participate in the management of casualties with ARS.

\section{CONCLUSIONS}

An extensive literature base has described the effects of radiation injury in humans and animal models. Many gaps in our understanding still exist and some injuries cannot be modeled in the laboratory, but several important findings have emerged. First, there is marked variability in radiation response within and across species. Second, many factors related to either the radiation or the recipient can affect the outcome of radiation injury. Third, traumatic and burn injuries can synergistically increase the mortality from radiation. Fourth, supportive care measures such as antibiotics, fluids, transfusion support, and possibly myeloid cytokines can reduce the mortality of radiation injury. These findings establish a foundation for the triage and treatment approaches outlined in this special issue. The need is critical for just-in-time guidance and surge capacity for irradiated casualty management. The REMM Web site ${ }^{89}$ was established to provide available evidence and expert opinion, including pre-and postevent training for health care workers and 
planners. RITN is a model for voluntary planning at centers across the country.

Author Affiliations: Dr DiCarlo is with the Radiation/Nuclear Countermeasures Program, National Institute of Allergy and Infectious Diseases, National Institutes of Health; Commander Maher is with the Office of Counterterrorism and Emerging Threats, US Food and Drug Administration; Dr Hick is with the Hennepin County Medical Center, University of Minnesota; Dr Hanfling is with the Department of Emergency Medicine, The George Washington University; Dr Dainiak is with Bridgeport Hospital, Yale University School of Medicine; Dr Chao is with the Duke University Bone Marrow and Stem Cell Transplant Program; Drs Bader and Coleman are with the Office of the Assistant Secretary for Preparedness and Response, US Department of Health and Human Services; Dr Weinstock is with the Dana-Farber Cancer Institute, Harvard Medical School.

Correspondence: Address correspondence and reprint requests to Dr David Weinstock, Dana-Farber Cancer Institute/Harvard Medical School, 45 Brookline Ave, D510B, Boston, MA 02115 (e-mail: DavidM_Weinstock@dfci.harvard.edu).

Received for publication December 16, 2010; accepted January 11, 2011.

DHHS provided funding to support this publication and convene the authors. The contents of the articles represent the personal views of the individual authors and do not necessarily express the opinion or policy of DHHS or its components. No statement in the articles should be construed as an official position of DHHS or its components.

Author Disclosures: Dr Weinstock is a paid consultant by Genzyme and Novartis.

Acknowledgments: The authors acknowledge the members and contributors of the National Institutes of Health's 2004 Animal Endpoint Working Group and the 2006 Ad-hoc Radiological and Nuclear Subcommittee Product Development Tools Working Group of the Weapons of Mass Destruction Steering and Integration Group. The authors also thank Alicia Livinski, biomedical librarian, National Institutes of Health Library, and Paula Murrain-Hill, program analyst, Office of the Assistant Secretary for Preparedness and Response, DHHS, for their assistance with the preparation of this article.

\section{REFERENCES}

1. Knebel AR, Coleman CN, Cliffer KD, et al. Allocation of scarce resources after a nuclear detonation: setting the context. Disaster Med Public Health Prep. 2011;5(Suppl 1):S20-S31.

2. Coleman CN, Weinstock DM, Casagrande R, et al. Triage and treatment tools for use in a scarce resources-crisis standards of care setting after a nuclear detonation. Disaster Med Public Health Prep. 2011;5(Suppl 1):S111-S121.

3. Hick JL, Weinstock DM, Coleman CN, et al. Healthcare system planning for and response to a nuclear detonation. Disaster Med Public Health Prep. 2011;5(Suppl 1):S73-S88.

4. Murrain-Hill P, Coleman CN, Hick JL, et al. Medical response to a nuclear detonation: creating a playbook for state and local planners and responders. Disaster Med Public Health Prep. 2011;5(Suppl 1):S89-S97.

5. Federal Emergency Management Agency, US Department of Homeland Security. FEMA fact sheet: National Planning Scenarios. 2009: http://www .fema.gov/pdf/media/factsheets/2009/npd_natl_plan_scenario.pdf. Published 2009. Accessed December 2, 2010.

6. Buddemeier BR, Dillon MB. Key Response Planning Factors for the Aftermath of a Nuclear Detonation. LLNL-TR-410067. http://www.remm.nlm .gov/IND_ResponsePlanning_LLNL-TR-410067.pdf. Published August 2009. Accessed February 3, 2011

7. Hall E. Acute effects of total-body irradiation. In: Hall E, ed. Radiobiology for the Radiologist. 5th ed. Philadelphia: Lippincott Williams \& Wilkins; 2000:124-135.

8. Fliedner TM, D Dörr H, Meineke V. Multi-organ involvement as a pathogenetic principle of the radiation syndromes: a study involving 110 case histories documented in SEARCH and classified as the bases of haematopoietic indicators of effect. BJR Suppl. 2005;27:1-8.
9. Institute of Medicine. Guidance for Establishing Crisis Standards of Care for Use in Disaster Situations: A Letter Report. Washington, DC: National Academies Press; 2009.

10. Waselenko JK, MacVittie TJ, Blakely WF, et al; Strategic National Stockpile Radiation Working Group. Medical management of the acute radiation syndrome: recommendations of the Strategic National Stockpile Radiation Working Group. Ann Intern Med. 2004;140(12):1037-1051.

11. Friesecke I, Beyrer K, Fliedner TM; METREPOL team. How to cope with radiation accidents: the medical management. Br J Radiol. 2001;74(878): 121-122.

12. Coleman CN, Hrdina C, Bader JL, et al. Medical response to a radiologic/ nuclear event: integrated plan from the Office of the Assistant Secretary for Preparedness and Response, Department of Health and Human Services. Ann Emerg Med. 2009;53(2):213-222.

13. Dainiak N, Waselenko JK, Armitage JO, et al. The hematologist and radiation casualties. Hemato Am Soc Hematol Educ Progr; 2003:473-496.

14. Fliedner TM, Chao NJ, Bader JL, et al. Stem cells, multiorgan failure in radiation emergency medical preparedness: a U.S./European Consultation Workshop. Stem Cells. 2009;27(5):1205-1211.

15. Cerveny T, MacVittie T, Young R. Acute radiation syndrome in humans. In: Walker R, Cerveny T, eds. Textbook of Military Medicine: Medical Consequences of Nuclear Warfare. Falls Church, VA: TMM Publications; 1989: 17-36.

16. Milyavsky M, Gan OI, Trottier M, et al. A distinctive DNA damage response in human hematopoietic stem cells reveals an apoptosisindependent role for 553 in self-renewal. Cell Stem Cell. 2010;7(2):186197.

17. Cheadle WG, Pemberton RM, Robinson D, Livingston DH, Rodriguez JL, Polk HC Jr. Lymphocyte subset responses to trauma and sepsis. J Trauma. 1993;35(6):844-849.

18. Maldonado MD, Venturoli A, Franco A, Nunez-Roldan A. Specific changes in peripheral blood lymphocyte phenotype from burn patients. Probable origin of the thermal injury-related lymphocytopenia. Burns. 1991;17 (3):188-192.

19. Fliedner TM, Graessle D, Meineke V, Dörr H. Pathophysiological principles underlying the blood cell concentration responses used to assess the severity of effect after accidental whole-body radiation exposure: an essential basis for an evidence-based clinical triage. Exp Hematol. 2007; 35(4)(Suppl 1):8-16.

20. Madonna GS, Ledney GD, Moore MM, Elliott TB, Brook I. Treatment of mice with sepsis following irradiation and trauma with antibiotics and synthetic trehalose dicorynomycolate (S-TDCM). J Trauma. 1991;31 (3):316-325.

21. Demidenko E, Williams BB, Swartz HM. Radiation dose prediction using data on time to emesis in the case of nuclear terrorism. Radiat Res. 2009; 171(3):310-319.

22. Anno GH, Young RW, Bloom RM, Mercier JR. Dose response relationships for acute ionizing-radiation lethality. Health Phys. 2003;84(5):565575.

23. Haskin FE, Harper FT, Goossens LHJ, et al. Appendices (NUREG/CR-6545) Vol 2. Washington, DC: Nuclear Regulatory Commission; 1997. Probabilistic Accident Consequence Uncertainty Analysis-Early Health Effects Uncertainty Assessment.

24. Haskin FE, Harper FT, Goossens LHJ, et al. Main Report (NUREG/CR-6545). Vol 1. Washington, DC: Nuclear Regulatory Commission; 1997. Probabilistic Accident Consequence Uncertainty Analysis_Early Health Effects Uncertainty Assessment.

25. Iijima S. Pathology of atomic bomb casualties. Acta Pathol Jpn. 1982;32 (Suppl 2):237-270.

26. Kishi HS. Effects of the "special bomb": recollections of a neurosurgeon in Hiroshima, August 8-15, 1945. Neurosurgery. 2000;47(2):441-445, discussion 445-446.

27. United Nations Scientific Committee on the Effects of Atomic Radiation. UNSCEAR 1988 Report to the General Assembly, With Annexes. Annex G: Early Effects in Man of High Doses of Radiation. New York: United Nations; 1988.

28. Dainiak N, Ricks RC. The evolving role of haematopoietic cell transplan- 
tation in radiation injury: potentials and limitations. BJR Suppl. 2005; 27:169-174.

29. Oak Ridge Institute for Science and Education. Radiation Emergency Center/Training Site Web site. http://orise.orau.gov/reacts. Accessed December 2, 2010 .

30. Hirama T, Tanosaki S, Kandatsu S, et al. Initial medical management of patients severely irradiated in the Tokai-mura criticality accident. BrJ Radiol. 2003;76(904):246-253

31. DiCarlo AL, Hatchett RJ, Kaminski JM, et al. Medical countermeasures for radiation combined injury: radiation with burn, blast, trauma and/or sepsis. report of an NIAID Workshop, March 26-27, 2007. Radiat Res. 2008;169(6):712-721.

32. Prasanna PG, Blakely WF, Bertho JM, et al. Synopsis of partial-body radiation diagnostic biomarkers and medical management of radiation injury workshop. Radiat Res. 2010;173(2):245-253.

33. Williams JP, Brown SL, Georges GE, et al. Animal models for medical countermeasures to radiation exposure. Radiat Res. 2010;173(4):557-578.

34. Barbero AM, Frasch HF. Pig and guinea pig skin as surrogates for human in vitro penetration studies: a quantitative review. Toxicol In Vitro. 2009; 23(1):1-13.

35. Hopewell JW. The skin: its structure and response to ionizing radiation. Int J Radiat Biol. 1990;57(4):751-773.

36. Simon GA, Maibach HI. The pig as an experimental animal model of percutaneous permeation in man: qualitative and quantitative observations-an overview. Skin Pharmacol Appl Skin Physiol. 2000;13(5):229-234.

37. Ledney GD, Elliott TB. Combined injury: factors with potential to impact radiation dose assessments. Health Phys. 2010;98(2):145-152.

38. Jackson IL, Vujaskovic Z, Down JD. Revisiting strain-related differences in radiation sensitivity of the mouse lung: recognizing and avoiding the confounding effects of pleural effusions. Radiat Res. 2010;173(1):10-20.

39. Dukhuongl E. Distribution of cobalt-60 in the rat as influenced by chelating agents. Nature. 1964;204:696-697.

40. Handford SW, Stonestreet PJ, Johnson PW, et al. The acute radiation syndrome in dogs after total-body exposure to a supralethal dose of ionizing radiation $\mathrm{Co}^{60} \mathrm{LD}_{100 / 88}$ hours. Radiat Res. 1960;13:712-725.

41. Melo DR, Lundgren DL, Muggenburg BA, Guilmette RA. Prussian Blue decorporation of 137Cs in beagles of different ages. Health Phys. 1996; 71(2):190-197.

42. MacVittie TJ, Farese AM, Jackson W III. Defining the full therapeutic potential of recombinant growth factors in the post radiation-accident environment: the effect of supportive care plus administration of G-CSF. Health Phys. 2005;89(5):546-555.

43. Lushbaugh C. Reflections on some recent progress in human radiobiology. In: Augenstein L, Mason R, Zelle M, eds. Advances in Radiation Biology. Vol 3. New York: Academic Press; 1969:277.

44. Fujita S, Kato H, Schull WJ. The LD50 associated with exposure to the atomic bombing of Hiroshima. J Radiat Res (Tokyo). 1989;30(4):359-381.

45. Levin SG, Young RW, Stohler RL. Estimation of median human lethal radiation dose computed from data on occupants of reinforced concrete structures in Nagasaki, Japan. Health Phys. 1992;63(5):522-531.

46. Laupa A, Anno G. Chernobyl Accident Fatalities and Causes. Washington, DC: Defense Nuclear Agency; 1990.

47. Allen RG, Brown FA, Logie LC, Rovner DR, Wilson SG Jr, Zellmer RW. Acute effects of gamma radiation in primates. Radiat Res. 1960;12:532559.

48. Eldred E, Trowbridge WV. Neurological and EEG findings in the monkey after total body x-irradiation. Electroencephalogr Clin Neurophysiol. 1953;5(2):259-270.

49. Haigh MV, Paterson E. Effects of a single session of whole body irradiation in the rhesus monkey. Br J Radiol. 1956;29(339):148-157.

50. Henschke UK, Morton JL. Mortality of rhesus monkeys after single total body irradiation. Am J Roentgenol Radium Ther Nucl Med. 1957;77(5): 899-909.

51. Schlumberger HG, Vazquez JJ. Pathology of total body irradiation in the monkey. Am J Pathol. 1954;30(6):1013-1047.

52. Dalrymple GV, Lindsay IR, Ghidoni JJ. The effect of 2-MEV whole-body x-irradiation on primates. Radiat Res. 1965;25:377-400.
53. Zoetelief J, Wagemaker G, Broerse JJ. Dosimetry for total body irradiation of rhesus monkeys with $300 \mathrm{kV}$ X-rays. Int J Radiat Biol. 1998;74 (2):265-272.

54. Broerse JJ, Van Bekkum DW, Hollander CF, Davids JA. Mortality of monkeys after exposure to fission neutrons and the effect of autologous bone marrow transplantation. Int J Radiat Biol Relat Stud Phys Chem Med. 1978; 34(3):253-264.

55. Zellmer R, Pickering J. Biological Effects of Nuclear Radiation in Primates. (AF-SAM-60-66). Brooks Air Force Base, TX: School of Aviation Medicine, US Aerospace Medical Center; 1960.

56. Stanley R, Seigneur L, Strike T. The Acute Mortality Response of Monkeys (Macacca mulatta) to Mixed Gamma-Neutron Radiations and $250 \mathrm{kVp} \times$ Rays. (SR66-23). Bethesda, MD: Armed Forces Radiobiology Research Institute; 1966.

57. Haus E. Chronobiology of the mammalian response to ionizing radiation. Potential applications in oncology. Chronobiol Int. 2002;19(1):77-100.

58. Kallman RF. The effect of dose rate on mode of acute radiation death of C57BL and BALB/c mice. Radiat Res. 1962;16:796-810.

59. Thomson JF, Tourtellotte WW, Carttar MS, Cox RS Jr, Wilson JE. Studies on the effects of continuous exposure of animals to gamma radiation from cobalt 60 plane sources. Am J Roentgenol Radium Ther Nucl Med. 1953;69(5):830-838.

60. Casarett AP. Modification of radiation injury. In: Casarett AP, ed. Radiation Biology. Englewood Cliffs, NJ: Prentice-Hall; 1968:236-265.

61. Grahn D. Acute radiation response of mice from a cross between radiosensitive and radioresistant strains. Genetics. 1958;43(5):835-843.

62. Garner RJ, Phemister RD, Angleton GM, Lee AC, Thomassen RW. Effect of age on the acute lethal response of the beagle to cobalt- 60 gamma radiation. Radiat Res. 1974;58(2):190-195.

63. McLaughlin MM, Dacquisto MP, Jacobus DP, Horowitz RE. Effects of the germfree state on responses of mice to whole-body irradiation. Radiat Res. 1964;23:333-349.

64. Hall JE, White WJ, Lang CM. Acidification of drinking water: its effects on selected biologic phenomena in male mice. Lab Anim Sci. 1980;30 (4 Pt 1):643-651.

65. Baranov AE, Guskova AK, Nadejina NM, Nugis VYu. Chernobyl experience: biological indicators of exposure to ionizing radiation. Stem Cells. 1995;13(Suppl 1):69-77.

66. Ledney G, Elliott T, Moore M. Modulations of mortality by tissue trauma and sepsis in mice after radiation injury. In: Mossman KL, Mills WA, eds. The Biological Basis of Radiation Protection Practice. Baltimore: Williams \& Wilkins; 1992:202-217.

67. Vorobiev AI. Acute radiation disease and biological dosimetry in 1993. Stem Cells. 1997;15(Suppl 2):269-274.

68. Brooks JW, Evans EI, Ham WT Jr, Reid JD. The influence of external body radiation on mortality from thermal burns. Ann Surg. 1952;136(3):533545.

69. Alpen EL, Sheline GE. The combined effects of thermal burns and whole body X irradiation on survival time and mortality. Ann Surg. 1954;140 (1):113-118

70. Baxter H, Drummond JA, Stephens-Newsham LG, Randall RG. Studies on acute total body irradiation in animals. I. Effect of streptomycin following exposure to a thermal burn and irradiation. Plast Reconstr Surg (1946). 1953;12(6):439-445.

71. Korlof B. Infection of burns. I. A bacteriological and clinical study of 99 cases. II. Animal experiments; burns and total body x-irradiation. Acta Chir Scand Suppl. 1956;209:1-144.

72. Mishima S, Yukioka T, Matsuda H, Shimazaki S. Mild hypotension and body burns synergistically increase bacterial translocation in rats consistent with a "two-hit phenomenon". J Burn Care Rehabil. 1997;18(1 Pt 1): 22-26.

73. Yan Y, Ran X, Wei S. Changes of immune functions after radiation, burns and combined radiation-burn injury in rats. Chin Med Sci J. 1995;10(2): 85-89.

74. Whitnall MH, Elliott TB, Harding RA, et al; Jackson WE3rd. Androstenediol stimulates myelopoiesis and enhances resistance to infection in gamma-irradiated mice. Int J Immunopharmacol. 2000;22(1):1-14. 
75. Ran X, Yan Y, Cheng T, Lin Y, Wei S, Zheng H. Effects of combined radiation and thermal burn injury on the survival of skin allograft and immune function in rats. Chin Med J (Engl). 1998;111(7):634-637.

76. Furth FW, Coulter MP, Miller RW, Howland JW, Swisher SN. The treatment of the acute radiation syndrome in dogs with aureomycin and whole blood. J Lab Clin Med. 1953;41(6):918-928.

77. Jackson DP, Sorensen DK, Cronkite EP, Bond VP, Fliedner TM. Effectiveness of transfusions of fresh and lyophilized platelets in controlling bleeding due to thrombocytopenia. J Clin Invest. 1959;38:1689-1697.

78. Perman V, Cronkite EP, Bond VP, Sorensen DK. The regenerative ability of hemopoietic tissue following lethal x-irradiation in dogs. Blood. 1962;19:724-737.

79. Sorensen DK, Bond VP, Cronkite EP, et al. An effective therapeutic regimen for the hemopoietic phase of the acute radiation syndrome in dogs. Radiat Res. 1960;13:669-685.

80. Baranov A, Gale RP, Guskova A, et al. Bone marrow transplantation after the Chernobyl nuclear accident. N Engl J Med. 1989;321(4):205212.

81. Gourmelon P, Benderitter M, Bertho JM, Huet C, Gorin NC, De Revel $\mathrm{P}$. European consensus on the medical management of acute radiation syndrome and analysis of the radiation accidents in Belgium and Senegal. Health Phys. 2010;98(6):825-832.

82. Ishii T, Futami S, Nishida M, et al. Brief note and evaluation of acuteradiation syndrome and treatment of a Tokai-mura criticality accident patient. J Radiat Res (Tokyo). 2001;42(Suppl):S167-S182.

83. Kuderer NM, Dale DC, Crawford J, Lyman GH. Impact of primary prophylaxis with granulocyte colony-stimulating factor on febrile neutropenia and mortality in adult cancer patients receiving chemotherapy: a systematic review. J Clin Oncol. 2007;25(21):3158-3167.

84. Farese AM, Hunt P, Grab LB, MacVittie TJ. Combined administration of recombinant human megakaryocyte growth and development factor and granulocyte colony-stimulating factor enhances multilineage hematopoietic reconstitution in nonhuman primates after radiation-induced marrow aplasia. J Clin Invest. 1996;97(9):2145-2151.

85. Neelis KJ, Dubbelman YD, Qingliang L, Thomas GR, Eaton DL, Wagemaker G. Simultaneous administration of TPO and G-CSF after cytoreductive treatment of rhesus monkeys prevents thrombocytopenia, accelerates platelet and red cell reconstitution, alleviates neutropenia, and promotes the recovery of immature bone marrow cells. Exp Hematol. 1997;25(10): 1084-1093.

86. Neelis KJ, Hartong SC, Egeland T, Thomas GR, Eaton DL, Wagemaker G. The efficacy of single-dose administration of thrombopoietin with coadministration of either granulocyte/macrophage or granulocyte colonystimulating factor in myelosuppressed rhesus monkeys. Blood. 1997;90 (7):2565-2573.

87. Weisdorf D, Chao N, Waselenko JK, et al. Acute radiation injury: contingency planning for triage, supportive care, and transplantation. Biol Blood Marrow Transplant. 2006;12(6):672-682.

88. Bader JL, Nemhauser J, Chang F, et al. Radiation event medical management (REMM): website guidance for health care providers. Prehosp Emerg Care. 2008;12(1):1-11.

89. National Library of Medicine, National Institutes of Health. Radiation Emergency Medical Management (REMM) Web site. http://www.remm.nlm .gov. Accessed April 2, 2010.

90. Davids MS, Case C Jr, Hornung R III, et al. Assessing surge capacity for radiation victims with marrow toxicity. Biol Blood Marrow Transplant. 2010;16(10):1436-1441

91. Weinstock DM, Case C Jr, Bader JL, et al. Radiologic and nuclear events: contingency planning for hematologists/oncologists. Blood. 2008;111 (12):5440-5445. 